\title{
COMPARING OF MARGINAL AND INTERNAL FIT OF MONOLITHIC ZIRCON CROWN FABRICATED BY 3D PRINTED DIE VERSUS CONVENTIONAL
}

\author{
Amany M. Korsel*
}

\begin{abstract}
Purpose: Evaluation of marginal and internal fit of monolithic zircon crown restoration fabricated by scanning three different die material ;3D printed resin versus stone and epoxy resin dies.

Materials and methods: A standardized Computer Numerical Control machine (CNC) will be used to fabricate a stainless steel master die simulating a prepared tooth with an occluso-gingival height of $6 \mathrm{~mm}$, a taper of $6^{\circ}$ and $1 \mathrm{~mm}$ shoulder circumferentially. The overall diameter of the die at the base is $8.5 \mathrm{~mm}$ Three groups of zircon crown (Prettau ${ }^{\circledR}$ Zirconia manufactured by Zirkonzahn ${ }^{\circledR}$ and E-Denstone $(\mathrm{B}) .10$ crowns per each group fabricated digitally from three different dies as follow: 1) First group (G1) 3D printed resin die (light cured methacrylate (Envision TEC). 2) Second group (GII), Epoxy resin die. 3) Third group (GIII) Type IV stone die (Zhermach spa, Bouazecchino ST, Badia polesine, Italy). Each crown fabricated from its specific die seated and stabilized on the master stainless steel die. Demark certain points on the crown margin and photographed using USB Digital microscope with a built-in camera (Scope Capture Digital Microscope, Guangdong, China) connected with an IBM compatible personal computer using a fixed magnification of 45X. Internal discrepancy of the copings was measured by a replica technique. Each coping was filled with light-body silicone (zetaplus, zhermack, italy), the replicas (heavy and light -body silicon) were carefully removed from the crown and sectioned mesio-distally into two equal segments with three regions measured on each section (margin, axial and occlusal), yielding 8 internal measurements for each coping. A digital image analysis system (Image J 1.43U, National Institute of Health, USA) was used to measure and qualitatively evaluate the gap width.
\end{abstract}

Results: Data analysis was performed in several steps. Initially, descriptive statistics for each group results. One-way ANOVA followed by pair-wise Tukey's post-hoc tests were performed to detect significance between all groups. The absolute marginal gap mean $\pm \mathrm{SD}$ values recorded for first group were $(18.0305 \pm 6.99717)$, for II group were $(41.0989 \pm 21.55940)$ and for III group were $(18.2960 \pm 7.177245)$. It was found that the highest absolute marginal gap mean value recorded for IIgroup followed by III group mean value. While the lowest absolute marginal gap mean value recorded for I group. The difference between all die groups was statistically significant as revealed with one-way ANOVA test $(\mathrm{p}=0.01)$. Pair-wise Tukey's post-hoc test showed non-significant differences while $(\mathrm{p}=0.99)$ between (groups III,I), While between (groups II, III) and (groups II, I) there is significant differences where $(\mathrm{p}=0.01)$.

\footnotetext{
* Assestant Professor in Fixed Prosthodontics Department. Faculty of Dentistry. Tanta University
} 


\begin{abstract}
Descriptive statistics, showing mean values and standard deviations (SD) for internal fit measured in $\mu \mathrm{m}$ recorded for all die groups are summarized as following: One way ANOVA showed that there is a significance between the three groups $\mathrm{p} \leq 0.05$ and also Pair-wise Tukey's post-hoc test showed non-significant differences ( $\mathrm{p}=0.926$ ) between group I and III, While the difference between group I and II was significant $\mathrm{P}=0.001$ and groupII and III was significant where $\mathrm{p}=0.001$.
\end{abstract}

Conclusion: With the limitation of this study, it was found that: 3D printed resin die provide a restoration with good marginal and internal fit. All the die materials provided crown restorations with acceptable fit.

\section{INTRODUCTION}

Dentistry is giving more and more attention to fulfill their needs using the highest technology. Esthetics and longevity of a restoration is a function of accurate manufacturing.

A good marginal fit seems to be one of the most important technical factors for the long term success of any restoration ${ }^{1-2}$.

The accuracy of fitting of any restoration is dependent on its marginal and internal fit. A large marginal opening allows more plaque accumulation and gingival sulcular fluid flow resulting in hypersensitivity, micro-leakage .Also lead to periodontal diseases and decrease of both the longevity and esthetics of the prosthetic restorations ${ }^{3}$

Fabrication of working cast and die is a critical step in fabrication of indirect restoration because it is the positive replica of the dental arch and the more accurate the working cast and die the more accurate will be the final restoration.

The die as a appositive reproduction of the prepared teeth and consist of a suitable hard substance must has ideal requirements as ; sufficient accuracy, dimensional stability, reproduction of fine details, good mechanical properties (high abrasion resistance to withstand manipulation procedure strong, durable) and also has good color contrast with the carving wax $^{4-5}$.

So many materials have been used for fabrication of working cast and die this includes ;stone die that has compatibility with all impression materials, reproduce fine details and sharp margins, dimensional stability and accuracy, produces consistent results, easy to use and low cost. While it has some disadvantages as susceptibility to abrasion during carving of wax pattern..$^{6-8}$

There is also resin dies, this includes epoxy, polyurethane resin, bis-acryl composite resin. These have some advantages as good mechanical properties and abrasion resistance, but still has some disadvantages as polymerization shrinkage, less dimensional stability and long procedures. Some other types of dies as electroplated dies, metal dies can be made by copper plating compound impression or silver plating rubber base impression and amalgam die but this type also need more time and long procedures .

The global additive manufacturing industry has progressed very quickly offering broader and high value applications. This accelerating shift has been due to its advantages over conventional manufacturing. ${ }^{4}$

3D printing, also known as additive manufacturing (AM), refers to various innovative processes that are used to manufacture threedimensional products. In additive manufacturing, successive layers of material are formed under computer control to create an object. These objects can be of almost any shape or geometry and are produced from a digital 3D model or other electronic data source. Great attention has been given to this subject recently since it offers new opportunities for polymers in factories of the future. 
Additive manufacturing may be a more appropriate term to use than 3D printing because it includes all processes that are "additive". The term "3D printing" applies more specifically to additive manufacturing processes that use a printer-like head for deposition of the material (e.g., material jetting), and 3D printing is now only one of the processes that is part of the additive manufacturing universe. Technical articles and standards generally use the term "additive manufacturing" to emphasize this broader meaning. ${ }^{4}$ Additive manufacturing applications appear to almost be limitless. Early use of 3D printing in the form of rapid prototyping focused on preproduction models. However, it is now being used to fabricate high-tech industrial (aerospace, medical/dental, automotive, electronic) and consumer (home, fashion, and entertainment) products, and today's materials include not only polymers but also metals and ceramics. ${ }^{5}$

Zirconium restorations, because of their improved esthetic appearance, chemical resistance, and biocompatibility, all-ceramic restorations are often preferred to porcelain-fused-to-metal (PFM) restorations. Recent developments in ceramic material science have resulted in improved strength properties of modern ceramic materials, and this has generated an increase in clinical acceptance of allceramic crowns. ${ }^{11}$

Zirconia restorations have been used successfully for years in dentistry owing to their biocompatibility and good mechanical properties. Because of their lack of translucency, zirconia cores are generally veneered with porcelain, which makes restorations weaker due to failure of the adhesion between the two materials. In recent years, all-ceramic zirconia restorations have been introduced in the dental sector with the intent to solve this problem. Besides the elimination of chipping, the reduced occlusal space requirement seems to be a clear advantage of monolithic zirconia restorations. However, scientific evidence is needed to recommend this relatively new application for clinical use..$^{12-15}$
Marginal and internal fit of dental restorations can be determined clinically by many methods as by radiographs, or dental explorer. The radiograph can offer information about the marginal fit of the crown during clinical practice especially when the margin is subgingival but parallel film placement is important to improve accuracy of this method ${ }^{16-18}$

The result was that neither the explorer nor the radiographs were better in detecting discrepancies than the impression method. Assif et $\mathrm{al}^{19}$. compared the use of explorer to the use of radiographs and to a technique using impression material in order to examine the marginal fit. However Hayashi et al. studied the effect of the explorer tip diameter and the visual condition in detection of vertical and horizontal gaps. A significant relation was found between explorer tip diameter and detection of horizontal gaps, but not for vertical steps. There was no significant difference among the visual conditions tested. ${ }^{20-23}$

The amount of clinical experience has an influence on the identification of those gaps.This finding suggests that the use of the explorer is characterized by subjectivity, introducing the bias of the investigator. Furthermore, this technique is not accurate with subgingivally placed margins. ${ }^{24,25}$

On the other hand in vitro methods for identification of those gaps as replica technique (RT).This technique can be used in vivo and in vitro by using a light body silicone to fill the space between the crown and the tooth. After removal from the crown restorations, the replicas were segmented, and measurements of the film thickness were performed with a light microscope. It is a very simple technique but its limitation is the possible distortion of silicone during examination steps. ${ }^{26}$

There is another technique as sectioning of the specimens, this technique is used by sectioning the specimens and studying them under an optical microscope The advantage of this technique is the accurate measurements; but the limitation of this method are sectioning of the specimens therefore, that the sections have limited surface of the 
circumferential surface of the sample and this will decrease the area to be evaluated.$^{27-29}$

Stereomicroscope is also used to evaluate the marginal discrepancies of restorations produced by different techniques. They took a 1:1 photograph of each of four sides of the die using a digital camera mounted on a tripod. Calibrated digital measurement software was used to measure the marginal openings. Although this technique can be considered very reliable but also have limitations as, if there is any change in the camera angle may change the measurement. Any overhanging in the restoration margin, this can not be evaluated because the microscope is set perpendicular to the margin of the restoration so the vertical overlap of the margin will show no vertical gap. ${ }^{30}$

Computerized tomography (CT) is one method used multiple projections of a crown restoration were taken as the source rotated around it A computer software used to analyze the projections and produce a 3 dimensional image (3D). This technique can offer images of the internal surface of the crowns and the margins with different angulations but its drawbacks are many like. ${ }^{31}$

3D fit assessment for dental restorations is a new triple-scan protocol using a non-contact scanner, three scans were performed: Coping, Master cast and Coping placed on master cast in a clinically correct final position. The coping and master dies were digitized, and surface tessellation/ triangulation language (STL) were generated with a scanner software for both the coping and the master cast then fitting of both (STL) of coping and master cast will be made assisted by the previously scanned position of coping placed on master cast. Then the same software will determine the misfit between the cast and the coping. This triple scan technique eliminated the disadvantages of 2D measurements as it increased the accuracy of evaluation by reaching every point in the interface between the restoration and the die. ${ }^{18}$
Every type of die materials has specific properties so the aim of this study is to compare the effect of different die materials and fabrication technique on the marginal accuracy and internal fit of zirconium crown restorations.

\section{MATERIALS AND METHODS}

The materials used in this study were Venile Polysiloxane impression material, Imprint $^{\mathrm{TM}}$ IIPenta $^{\mathrm{TM}}$ Heavy Body) used in combination with Imprint II Garant ${ }^{\mathrm{TM}}$ light body (manufactured by $3 \mathrm{M}{ }^{\circledR}$.). Zirconium block for milling: Prettau ${ }^{\circledR}$ Zirconia manufactured by Zirkonzahn ${ }^{\circledR}$ and E-Denstone ${ }^{\circledR}$. 3Dprinting resin composed of light cured methacrylate (Envision TEC). Type four dental stone (Zhermach spa, Bouazecchino ST, Badia polesine, Italy)

A standardized Computer Numerical Control machine $(\mathrm{CNC})$ will be used to fabricate a stainless steel master die simulating a prepared tooth with an occluso-gingival height of $6 \mathrm{~mm}$, a taper of $6^{\circ}$ and $1 \mathrm{~mm}$ shoulder circumferentially. The overall diameter of the die at the base is $8.5 \mathrm{~mm}$.

Three groups of zirconia crowns were classified, (10 crowns per each), according the type of die:

1) First group (G1) 3D printed resin die: The stainless steel die was scanned using Zirkonzahn S600 ARTI ${ }^{\circledR}$ optical scanner after it is sprayed with scanning spray to fabricate a $3 \mathrm{D}$ printed resin die.

2) Second group (GII)(epoxy die): The master St. St. die was scanned for milling of the epoxy resin die.

3) Third group (GIII) stone die: Poly venilesiloxan impression was taken for the master die and poured with type 4 stone (Zhermach spa, Bouazecchino st. Badia polesine, Italy) to make the stone die. (Fig1,A,B,C) 


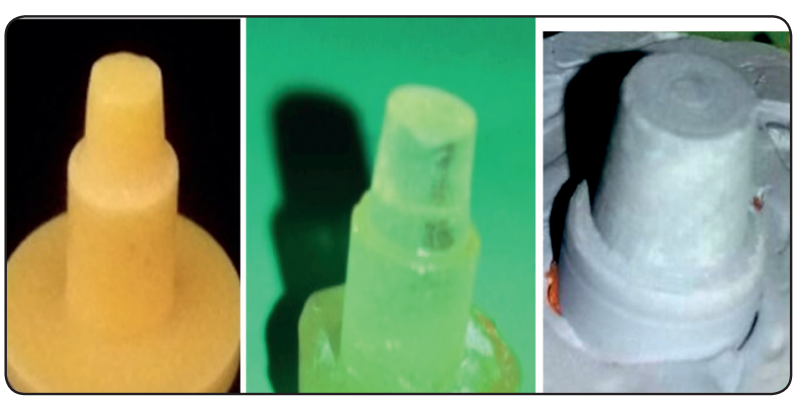

Fig. (1) A,B,C A) 3D printing die B) epoxy die C) stone die

Each die of the three groups was sprayed with scanning spray to prevent reflection and optical scanned using Zirkonzahn S600 ARTI ${ }^{\circledR}$ optical scanner for designing of zirconium crowns using Zirkonzahn -software. The crowns of all groups were milled from semi-sintered zirconia, by Zirkonzahn® Milling Unit M3. After milling, all the frameworks were sintered to full density, in a special sintering furnace (LavaTMFur-nace 200) at a temperature of $1.500{ }^{\circ} \mathrm{C}$. Once they had been delivered, all frameworks were examined for deformity and debris.Fig2

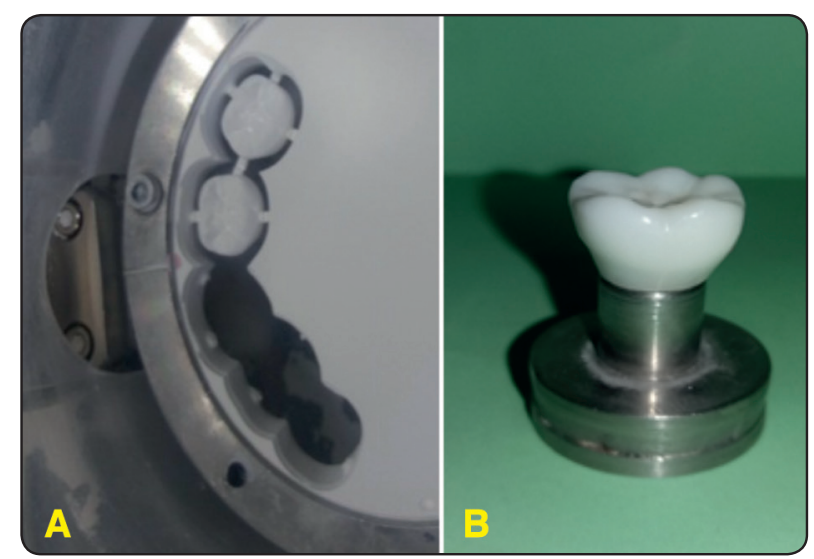

Fig. (2) A) Milling of the zirconia crowns Zircon block B) Zircon crown from the seated on the master die

\section{Marginal gap evaluation:}

A specially designed device was machined in order to aid in specimen holding during gap evaluation. It consisted of 2 parts: Fixed base portion, rectangular in shape $(10 \mathrm{~cm}$ length of 1.2 $\mathrm{cm}$ height and $2.3 \mathrm{~cm}$ width). The stainless steel die will rest on this portion., and upper movable portion rectangular in shape $(10 \mathrm{~cm}$ length of $1.2 \mathrm{~cm}$ height and $2.3 \mathrm{~cm}$ width). This portion is connected to the base portion through 2 metallic rods surrounded by spring wire to control the compressibility of the upper portion and fixed by tightening plastic caps, it is lined by rubber sheet to prevent friction that may cause any damage to the specimen.

Each specimen was photographed circumferentially around the margin from The external end of the crown to the end of the finish line of the die, using USB Digital microscope with a built-in camera (Scope Capture Digital Microscope, Guangdong, China) connected with an IBM compatible personal computer using a fixed magnification of $45 \mathrm{X}$.

A digital image analysis system (Image J 1.43U, National Institute of Health, USA) was used to measure and qualitatively evaluate the gap width. Within the Image $\mathbf{J}$ software, all limits, sizes, frames and measured parameters are expressed in pixels. Therefore, system calibration was done to convert the pixels into absolute real world units. Calibration was made by comparing an object of known size (a ruler in this study) with a scale generated by the Image $\mathbf{J}$ software. Specimens were held in place over their corresponding dies using a specially designed and fabricated holding device. Shots of the margins were taken for each specimen. Then morphometric measurements were done for each shot eight equidistant landmarks along the cervical circumference for each surface of the specimen (Mesial, buccal, distal, and lingual). Then the data obtained were collected, tabulated and then subjected to statistical analysis

\section{Internal gap evaluation}

Internal discrepancy of the copings was measured by a replica technique. Each coping was filled with light-body silicone (zetaplus, zhermack, italy) . 


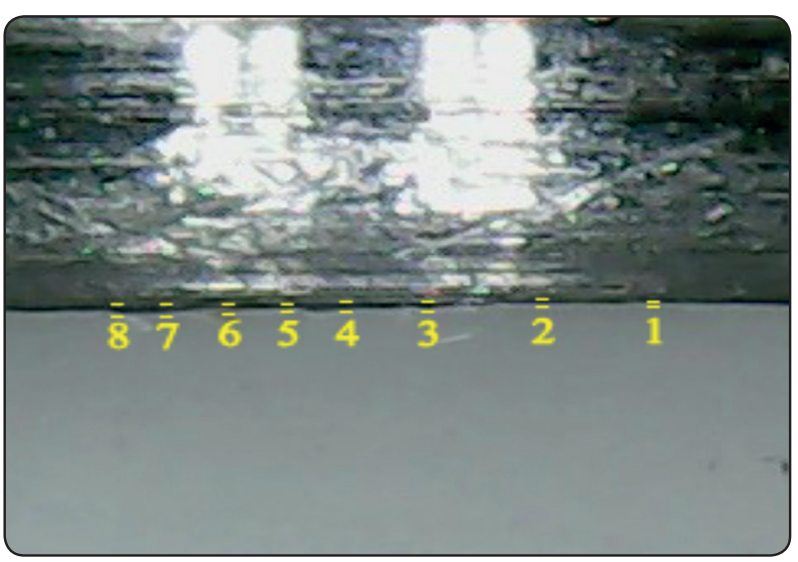

Fig. (3) Shot of the margin

The respective master die was inserted under a constant load $(750 \mathrm{~g})$ for $10 \mathrm{~min}$, by means of a modified parallelometer. After the light-body silicone had set, the coping was removed. Since it was not possible to remove the light-body silicone from the interior portions of the crown without distorting it, a heavy-body silicone was used to stabilize the light-body silicone. Using a razor blade $\left(n^{\circ} .15 c\right)$ the replicas( heavy and light -body silicon) were carefully removed from the crown and sectioned mesio-distally into two equal segments with three regions measured on each section (margin, axial and occlusal), yielding 8 internal measurements for each coping Fig3

One From the two obtained replica sections was cut bucco-lingually, with three regions measured on each section margin, axial and occlusal), yielding 4 internal measurements for each coping.(Fig 4) Each specimen was photographed using USB Digital microscope with a built-in camera (Scope Capture Digital Microscope, Guangdong, China) connected with an IBM compatible personal computer using a fixed magnification of 45X. A digital image analysis system (Image J 1.43U, National Institute of Health, USA) was used to measure and qualitatively evaluate the gap width. Within the Image J software, all limits, sizes, frames and measured parameters are expressed in pixels.

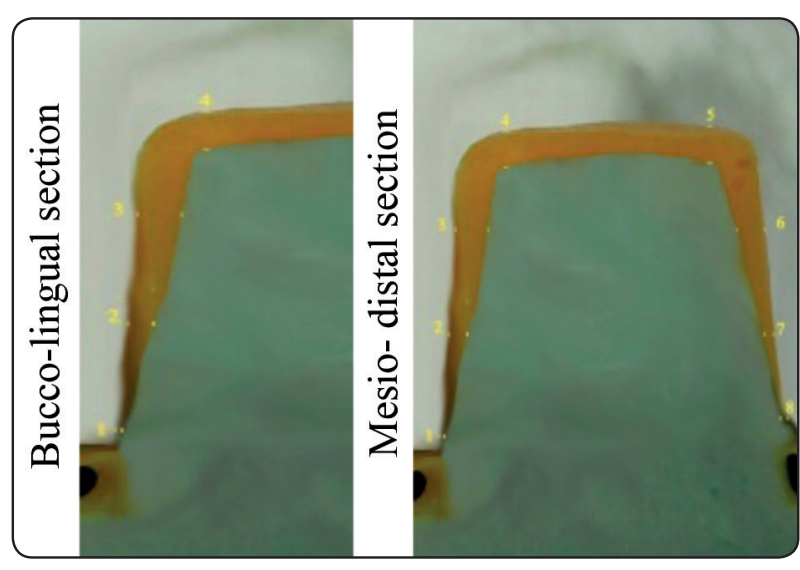

Fig. (4) The replica segment (heavy and light -body silicon)

\section{RESULTS}

Data analysis was performed in several steps. Initially, descriptive statistics for each group results. One-way ANOVA followed by pair-wise Tukey's post-hoc tests were performed to detect significance between all groups. Student t-test was done between die type groups. Statistical analysis was performed using Graph-Pad In Stat statistics software for Windows (www.graphpad.com). P values $\leq 0.05$ are statistically significant in all tests.

Descriptive statistics, showing mean values and standard deviations (SD) for absolute marginal gap measured in $\mu \mathrm{m}$ recorded for all die groups are summarized in table (I).

The absolute marginal gap mean \pm SD values recorded for group I were $(18.0305 \pm 6.99717)$ with minimum value (10.00) and maximum value (31.62) . The marginal gap mean \pm SD values recorded for group II were $(41.0989 \pm 21.55940)$ with minimum value (10.00) and maximum value (90.55). Also, the absolute marginal gap mean \pm SD values recorded for group IIIwere (18.2960 \pm 7.177245$)$ with minimum value (.00) and maximum value 30.00 . It was found that the highest absolute mean value recorded for groupII followed by group III.While the lowest absolute marginal gap mean value recorded for group I. The difference between all Die groups was statistically significant as revealed with one-way ANOVA test $(\mathrm{p}=0.01)$. and $\mathrm{F}$ value was 37.227. 
Pair-wise Tukey's post-hoc test showed non-significant differences $(\mathrm{p}=0.99)$ between (group III and group I), While (group II versus group III)and (group II versus group I) there is significant different, where $(\mathrm{p}=0.01)$

TABLE (I) Showing the absolute marginal fit of the three Die groups

\begin{tabular}{|c|c|c|c|c|c|c|c|}
\hline \multirow{2}{*}{ Groups } & \multirow{2}{*}{} & & & \multicolumn{2}{|c|}{$95 \%$ Confidence Interval for Mean } & \multirow{2}{*}{} \\
\cline { 5 - 7 } & $\mathrm{N}$ & Mean & Std. Deviation & Lower Bound & Upper Bound & Minimum & Maximum \\
\hline 3D & 40 & 18.0305 & 6.99717 & 15.7927 & 20.2683 & 10.00 & 31.62 \\
\hline epoxy & 40 & 41.0989 & 21.55940 & 34.2038 & 47.9939 & 10.00 & 90.55 \\
\hline stone & 40 & 18.2960 & 7.17724 & 16.0006 & 20.5914 & .00 & 30.00 \\
\hline Total & 120 & 25.8085 & 17.41127 & 22.6612 & 28.9557 & .00 & 90.55 \\
\hline
\end{tabular}

Signficance between and within the three groups

\begin{tabular}{|c|c|c|c|c|c|}
\hline \multicolumn{7}{|c|}{ One way ANOVA } \\
\hline & $\begin{array}{c}\text { Sum of } \\
\text { Squares }\end{array}$ & Df & $\begin{array}{c}\text { Mean } \\
\text { Square }\end{array}$ & F & Sig. \\
\hline $\begin{array}{c}\text { Between } \\
\text { Groups }\end{array}$ & 14029.159 & 2 & 7014.580 & 37.227 & $.01^{*}$ \\
\hline $\begin{array}{c}\text { Within } \\
\text { Groups }\end{array}$ & 22045.966 & 117 & 188.427 & & \\
\hline Total & 36075.125 & 119 & & & \\
\hline
\end{tabular}

Pair-wise Tukey's post-hoc test

\begin{tabular}{|c|c|c|}
\hline \multirow{2}{*}{ Tukey test } & Sig. \\
\hline \multirow{2}{*}{$3 \mathrm{D}$} & epoxy & $.01^{*}$ \\
\cline { 2 - 3 } & stone & .99 \\
\hline \multirow{2}{*}{ epoxy } & $3 \mathrm{D}$ & $.01^{*}$ \\
\cline { 2 - 3 } & stone & $.01^{*}$ \\
\hline \multirow{2}{*}{ stone } & $3 \mathrm{D}$ & .99 \\
\cline { 2 - 3 } & epoxy & $.01^{*}$ \\
\hline
\end{tabular}

The data of internal fit along the fitting surface of the monolithic crown were Table II

Descriptive statistics, showing mean values and standard deviations (SD) for internalfit measured in $\mu \mathrm{m}$ recorded for all die groups are summarized in table (II).

Table (II) internal fit of the zircon crown in the three groups.

\begin{tabular}{|c|c|c|c|c|c|}
\hline & $\begin{array}{c}\text { Sum of } \\
\text { Squares }\end{array}$ & Df & $\begin{array}{c}\text { Mean } \\
\text { Square }\end{array}$ & F & Sig. \\
\hline $\begin{array}{c}\text { Between } \\
\text { Groups }\end{array}$ & 61742.244 & 2 & 30871.122 & 12.063 & $.001^{* *}$ \\
\hline $\begin{array}{c}\text { Within } \\
\text { Groups }\end{array}$ & 237996.202 & 93 & 2559.099 & & \\
\hline Total & 299738.445 & 95 & & & \\
\hline
\end{tabular}

\begin{tabular}{|c|c|c|}
\hline \multicolumn{2}{|c|}{ Tukeytest } & Sig. \\
\hline \multirow{2}{*}{$3 \mathrm{D}$} & epoxy & $.001^{* *}$ \\
\cline { 2 - 3 } & stone & .926 \\
\hline \multirow{3}{*}{ epoxy } & $3 \mathrm{D}$ & $.001^{* *}$ \\
\cline { 2 - 3 } & stone & $.001^{* *}$ \\
\hline \multirow{3}{*}{ stone } & $3 \mathrm{D}$ & .926 \\
\cline { 2 - 3 } & epoxy & $.001^{* *}$ \\
\hline
\end{tabular}

One way ANOVA showed that there is a significance between the three groups $\mathrm{p} \leq 0.05$

Pair-wise Tukey's post-hoc test showed non-significant $(\mathrm{p}=0.926)$ differences between 3D printed die group and Stone group, While the difference between 3D group and Epoxy group was significant $\mathrm{p}=0.001$ and also the difference between the Stone group and Epoxy group significance where $\mathrm{p}=0.001$ 


\section{DISCUSSION}

Fabrication of a good fitting dental prosthesis is directly related to the accurate fabrication of a master cast and die. A working cast and die have to accurately dublicate the teeth in the patients mouth in order to get an accurate final restoration. So the present study highlights the importance of a precise die material by comparing the marginal fit of three groups of monolithic zircon crown restorations fabricated using a new technique as 3Dprinted resin die versus the conventional stone and epoxy dies. ${ }^{32}$

The accuracy of $3 \mathrm{D}$ printed resin dies is important to evaluate the impact of this new technology on the working cast and die. In the current study the marginal fit of monolithic zirconium crowns fabricated using different die material was evaluated. Auto-polymerising resins offer strength, rigidity, and dimensional stability if immediate invest ${ }^{36}$.

Paquette et al; 2000 evaluated whether a retarded setting reaction could improve the accuracy of an epoxy resin die system, and compared the accuracy of this system with gypsum-based die materials. They concluded that retarding the setting reaction of an epoxy resin die material improved its accuracy of the materials tested, retarded set epoxy dies had the least mean dimensional change from the metal master. Epoxy resin die materials had a net shrinkage, but the gypsum-based materials had a net expansion. The epoxy resin materials exhibited more variability than the gypsum-based materials ${ }^{38}$.

Thus to overcome the disadvantages of auto polymerized resin, recent technologies like 3D printing is being used to print a resin die in a layer by layer manner to result in three dimensional objects which has good dimensional stability. This was improved because of the use of Otoflash ${ }^{\mathrm{R}}$ light curing champer. The Otoflash is a light polymerization chamber for the hardening/curing of light curing resins and wax. Two photoflash lamps at the bottom of the curing chamber operate in a work mode with a frequency of 10 flashes per second. The photo- flash lamps produce a very intensive light radiation in a spectrumfrom 300 up to $700 \mathrm{~nm}$. Because of this intensive light radiation, a better hardening of the materials is possible, resulting in materials with good physical values and reduced content of residual monomer versus using other lamp types with a different light emitting spectrum. ${ }^{39}$

Chaffee et al; evaluated the ability of an epoxy resin die material and a type IV dental stone to dimensionally reproduce a custom-fabricated metal die. They found that this epoxy die system will provide a degree of dimensional accuracy comparable to gypsum when used with addition silicone impression material ${ }^{36}$.

In the present study, for evaluation of the marginal gap, USB Digital microscope with a built-in camera (Scope Capture Digital Microscope, Guangdong, China) connected with an IBM compatible personal computer using a fixed magnification of $45 \mathrm{X}$. While replica technique was used for internal gap evaluation because it is non destructive method and no sectioning was made because sectioning can affect the adaptation of the restoration on the die. The replica technique can also give the horizontal marginal gab that can be compared with the absolute marginal gap detected the digital microscope.

Trifkovic et al; evaluated the application of electron microscope and replica technique in marginal and internal gap measurements, they found that electron microscope is reliable regarding marginal gap evaluation. The values of marginal fits in ceramic crowns evaluated by the replica technique were statistically significantly lower compared to the values obtained by Electron Microscope ${ }^{35}$

Some studies evaluated effect of the crown preparation margin and die type on the marginal accuracy of fiber-reinforced composite crowns. They compared the chamfer and shoulder finish line on stone and epoxy dies. They found that significant differences were found among the die material used for the shoulder margin design. However, there was 
no significant difference between light chamfer and deep chamfer margin designs for both die materials. ${ }^{37}$

Vaswani et al. evaluated the marginal accuracy in porcelain fused to metal copings fabricated in two different finish lines using three different die materials Type IV dental stone, resin modified stone, and epoxy resin. They found that copings fabricated on epoxy resin dies exhibited highest value of vertical marginal discrepancy, where as least value was determined for copings constructed on dies fabricated from resin modified gypsum. ${ }^{34}$

In the current study, the 3D printed resin die proved to be more accurate than stone die and epoxy die thus all crown restorations fabricated using 3D printed resin die exhibited less marginal and internal gap this is attributed to the dimensional stability of it compared to the epoxy resin which has a high dimensional changes and 3D printed resin die has higher strength than stone die which is prone to fracture or abrasion.

\section{CONCLUSION}

With the limitation of this study we concluded that:

- 3D printed resin die provide a restoration with good marginal and internal fit.

- All the die materials provided crown restorations with acceptable fit

\section{REFERENCES}

1. Abduo J, Lyons K, Swain M. Fit of zirconia fixed partial denture: A systematic review. J Oral Rehab. 2010;37(11):866-76

2. Gulce S, Nilgun O, Ozgur I, Nalan B. Evaluation of marginal fit of two all-ceramic copings with two finish lines. Eur J Dent. 2012; 6(2): 163-168

3. JaafarA, Karl M, Mohammed B. Trends in ComputerAided Manufacturing in Prosthodontics: A Review of the Available Streams. Int J of Dent 2014; 2014(1):783948.

4. Edward H, Nigel J . 3D printing in prosthodontics. F D J 2014, pp. 152-157
5. Sun J,Zhang Q. The applicion of rapid prototyping in prothodontics. J Proth 2012 Dec,21(8) 621-4

6. Bloem TJ, Czerniawski B, Luke J, Lang BR. Determination of the accuracy of three die systems. J Prosthet Dent 1991;65:758-762.

7. James Ragain C, Mark Groskko L, Raj M, Thomas Ryan N,William Johnston M. Detail reproduction, contact angles and die hardness of elastomeric impression and gypsum die material combinations. Int J Prosthodont 2000;13:214-220.

8. Kenyon BJ, Hagge MS, Leknius C, Daniels WC, Weed ST.Dimensional accuracy of 7 die materials. J Prosthet Dent 2005;14:25-31.

9. Dawood, A. Morti, Swart,V.3D Printing in Dentistry.BDJ 2015.219;521-529

10. Miyazaki, T.; Hotta, Y.; Kunii, J.; Kuriyama, S.; Tamaki, Y. A review of dental CAD/CAM: current status and future perspectives from 20 years of experience. Dent. Mater. J. 2009, 28, 44-56.

11. Holand W, Appel C, Ritzberger C, Rothbrust F, Kuppert $\mathrm{H}$, et al. Future perspectives of biomaterials for dental restoration. J Eur Ceramic Soc 2009, 29: 1291-1297.

12- Mundhe K, Jain V, Pruthi G, et al. Clinical study to evaluate the wear of natural enamel antagonist to zirconia and metal ceramic crowns. J Prosthet Dent.2015;114:358363.

13- Chang JS, Ji W, Choi $\mathrm{CH}$, et al. Catastrophic failure of a monolithic zirconia prosthesis. J Prosthet Dent. 2015;113:8690.

14- Moscovitch M. Consecutive case series of monolithic and minimally veneered zirconia restorations on teeth and implants: up to 68 months. Int J Periodontics Restorative Dent. 2015;35:315-323.

15. Nurdan Polat Sagsoz, Nuran Yanikoğlu, Omer Sagsoz :Effect of Die Materials on the Fracture Resistance of CAD/CAM Monolithic.Crown Restorations OHMD 2016. 15. N.3,

16. Romeo E, Iorio M, Storelli S, Camandona M, Abati S. Marginal adaptation of full coverage CAD/CAM restorations: In vitro study using a non-destructive method. Minerva Stomatol. 2009 Mar;58(3):61-72.

17. Tan PL, Gratton DG, Diaz-Arnold AM, Holmes DC. An in vitro comparison of vertical marginal gaps of CAD/CAM titanium and conventional cast restorations. J Prosthodont. $2008 \mathrm{Jul} ; 17(5): 378-83$. 
18 - Isabella Lima Arrais Ribeiro, Fernanda Campos, Rafael Santiago Sousa, Maria Luiza Lima Alves.Marginal and internal discrepancies of zirconia copings: Effects of milling system and finish line design. Indian Journal of Dental Reasersh 2015; 26 ( 1 ) : 15-20

19. Assif D, Antopolski B, Helft M, Kaffe I. Comparison of methods of clinical evaluation of the marginal fit of complete cast gold crowns. J ProsthetDent.1985 ;54(1):20-4.

20. Hayashi M, Wilson NH, Ebisu S, Watts DC. Influence of explorer tip diameter in identifying restoration margin discrepancies. J Dent. 2005;33(8):669-74.

21. Leknius C, Giusti L, Chambers D, Hong C. Effects of clinical experience and explorer type on judged crown margin acceptability. J Prosthodont. 2010 Feb;19(2):138-43.

22. Christensen GJ. Marginal fit of gold inlay castings. J ProsthetDent.1966;16(2):297-305.

23. Boening KW, Wolf BH, Schmidt AE, Kastner K, Walter $\mathrm{MH}$. Clinical fit of proceraAllCeram crowns. J Prosthet Dent. 2000 Oct;84(4):419-24.

24. Coli P, Karlsson S. Fit of a new pressure-sintered zirconium dioxide coping. Int J Prosthodont. 2004 Jan-Feb; 17(1):59-64.

25. Nakamura T, Tanaka H, Kinuta S, Akao T, Okamoto $\mathrm{K}$, Wakabayashi $\mathrm{K}$, et al. In vitro study on marginal and internal fit of CAD/CAM all-ceramic crowns. Dent Mater J.2005 Sep;24(3):456-9.

26. Kokubo Y, Nagayama Y, Tsumita M, Ohkubo C, Fukushima S, Vult von SteyernP.Clinical marginal and internal gaps of in-ceram crowns fabricated using the GN-I system.J Oral Rehabil.2005;32(10):753-8.

27. Kokubo Y, Ohkubo C, Tsumita M, Miyashita A, Vult von Steyern P, Fukushima S.Clinical marginal and internal gaps of proceraAllCeram crowns. J Oral Rehabil. 2005 Jul;32(7):526-30.

28. Reich S, Uhlen S, Gozdowski S, Lohbauer U. Measurement of cement thickness under lithium disilicate crowns using an impression material technique. Clin Oral Investig. 2011 Aug;15(4):526.
29. Brukl CE, Philp GK. The fit of molded all-ceramic, twin foil, and conventional ceramic crowns.JProsthet Dent. 1987 Oct;58(4):408-13.

30. Hunt JL, Cruickshanks-Boyd DW, Davies EH. The marginal characteristics of collarless bonded porcelain crowns produced using a separating medium technique. Quintessence Dent Technol. 1978 Nov;2(9):21-6.

31. Tan P, Gratton D, Diaz A, Holmes D. An in vitro comparison of vertical marginal gaps of CAD/CAM titanium and conventional cast restorations. J Prosthodont. 2008; 17(5):378-83.

32. Pelekanos S, Koumanou M, Koutayas SO, Zinelis S, Eliades G. Micro-CT evaluation of the marginal fit of different in-ceram alumina copings. Eur J Esthet Dent. 2009 Autumn;4(3):278-92.

33. Ayad MF. Effect of the crown preparation margin and die type on the marginal accuracy of fiber-reinforced composite crowns. J Contemp Dent Pract. 2008 Feb 1;9(2):9-16

34. Vaswani PL, Sanyal PK, Gosavi SY, Kore AR. An In-vitro Comparative Stereomicroscopic Analysis and Evaluation of Marginal Accuracy in Porcelain Fused to Metal Copings Fabricated in Two Different Finish Lines Using Variant Die Materials. J ClinDiagn Res. 2017 Jan;11(1):ZC01-ZC05

35. B. Trifkovic, I. Budak, A. Todorovic, J. Hodolic, T. Puskar, D. Jevremovic, D. Vukelic Application of Replica Technique and SEM in Accuracy Measurement of Ceramic Crowns Measurement. Science Review 2012 Jan. 12(3):90-97

36. Chaffee NR1, Bailey JH, Sherrard DJ.Dimensional accuracy of improved dental stone and epoxy resin die materials. Part I: Single die.J Prosthet Dent. 1997 Feb;77(2):131-5.

37. Iglesias A, Powers JM, Pierpont HP. Accuracy of wax, autopolymerized and light polymerized resin pattern material. J Prosthodont. 1996;5(3):201-205

38. Paquette JM1, Taniguchi T, White SN.Dimensional accuracy of an epoxy resin die material using two setting methods.J Prosthet Dent. 2000 Mar;83(3):301-5.

39. C. Decker, C. Bianchi.Ultrafast hardening of a modelling paste by UV-curing of a polyamide filled acrylic resin.JOURNAL OF MATERIALS SCIENCE 40 (2005) 5491 - 5497 